\title{
Processos de Reestruturaçáo Curricular e Formaçáo Continuada de Professores no PROEJA/ES: o meio ambiente como eixo articulador
}

\author{
Mirian Jonis Silva \\ Sandra Escovedo Selles ${ }^{2}$ \\ Rui Marques Vieira ${ }^{3}$
}

\section{RESUMO \\ PROCESSOS DE REESTRUTURAÇÃO CURRICULAR E FORMAÇÃO CONTINUADA DE PROFESSORES NO PROEJA/ES: O MEIO AMBIENTE COMO EIXO ARTICULADOR.}

Este texto tem como foco o processo de reestruturação curricular desencadeado pela implementação do Programa de Educação Profissional Técnica de Nível Médio integrado ao Ensino Médio, na Modalidade Educação de Jovens e Adultos (PROEJA) no Instituto Federal do Espírito Santo, desenvolvido a partir de uma pesquisa de caráter interinstitucional. O artigo discute a problemática ambiental implicado na construção coletiva desta proposta curricular, articulando a abordagem de questóes sociais no ensino de Biologia às especificidades da EJA. O enfoque interdisciplinar buscado aborda a problemática ambiental para além da perspectiva estritamente biológica, englobando também as implicaçóes sociais, políticas e econômicas. Adotando como estratégia investigativa o trabalho colaborativo entre pesquisadores e professores, a análise orienta-se a partir do registro das reunióes realizadas entre eles e da avaliação do material curricular produzido pelos docentes. A análise das primeiras versóes do material evidencia a predominância de uma concepção de ambiente que articula fatores naturais,

1 Licenciada em Ciências Biológicas pela Universidade Federal do Rio de Janeiro, mestre e doutora em Educação pela Pontifícia Universidade Católica do Rio de Janeiro. Professora Adjunta e Vice-Diretora do Centro de Educação da Universidade Federal do Espírito Santo. Tem experiência em formação inicial e continuada de professores, com ênfase no ensino de Ciências e Biologia para a Educação Básica, Educação de Jovens e Adultos e Educação Popular.

2 Professora Associada da Universidade Federal Fluminense. É coordenadora do Programa de Pós-Graduação em Educação (2011-2013). Tem experiência na área de Educação, com ênfase em Educação em Ciências, desenvolvendo pesquisas principalmente nos seguintes temas: ensino de biologia, formação de professores de Ciências e Biologia, livro didático, conhecimento escolar e estudos históricos do currículo de Ciências e Biologia. É do Programa de Pós-Graduação em Educação da Universidade Federal Fluminense e bolsista de produtividade 1D do CNPq.

3 Departamento de Educação, Universidade de Aveiro. Desenvolve pesquisa na área de Educação Ambiental, Currículo e Formação de Professores.

Ci. Huma. e Soc. em Rev. RJ, EDUR, vol. 35, n. 2, jul / dez, p. 77-96, 2013 
socioculturais, políticos e econômicos. Nessas concepçóes de ambiente, encontra-se subjacente a noção de desequilíbrio, seja na dinâmica dos processos ecossistêmicos, seja nas relaçóes entre os humanos e destes com a natureza. Assim, o desequilíbrio ambiental é visto como consequência direta do modelo de desenvolvimento econômico e do tipo de racionalidade envolvida. Palavras-chave: Educação ambiental; EJA; currículo.

\section{ABSTRACT \\ CURRICULUM CHANGE AND IN-SERVICE TRAINING OF TEACHERS: ENVIRONMENT AS A CROSS CURRICULUM THEME IN THE CASE OF PROEJA/ES.}

This article focuses on the curriculum development process trigged by the implementation of the Program of Technical and Professional Education for High School in the Youth and Adult Education (PROEJA) in the Espirito Santo Federal Institute. The research involves more than one institution and aims to discuss environmental issues in the curriculum proposal through a collaborative approach. An interdisciplinary approach is adopted and addresses environmental issues beyond a strictly biological sense, involving social, political and economic implications. The research uses a collaborative approach between researchers and teachers and organized meeting with them. The analysis uses the meeting records and the evaluation of the curriculum materials produced by the teachers. The analysis suggests that the main environment conception in the materials shows relationships between natural, social and cultural, political and economic factors. The notion that underlines these conceptions is that there is an unbalance not only in the dynamic of the ecosystem processes but also between humans and them with nature. Thus, environmental unbalance is seen as a straight result of the economical development model as well as the kind of rationality involved in it. Key words: environmental education; Youth and Adult Education; curriculum

\section{INTRODUÇÃO}

O presente artigo configura o esforço de síntese de uma etapa de um projeto de pesquisa realizado por um grupo interinstitucional que reúne pesquisadores, pós-graduandos e bolsistas de Iniciação Científica da Universidade Federal do Espírito Santo (UFES) e do Instituto Federal do Espírito Santo (IFES). Desde 2007, o grupo vem desenvolvendo um estudo de caso que focaliza o processo de reestruturação curricular desencadeado pela implementação do Programa de Educação Profissional Técnica de Nível Médio integrado ao Ensino Médio, na Modalidade ducação de Jovens e Adultos (PROEJA) no IFES. De setembro de 2010 a junho de 2011, a 
parceria se ampliou com a possibilidade de realização de estudos junto à Universidade Federal Fluminense $e^{4}$ e o CIDTFF - Centro de Investigação Didáctica e Tecnologia na Formação de Formadores, da Universidade de Aveiro, em Portugal.

Assim, trata-se de um estudo de caso realizado a muitas mãos, sob múltiplos olhares, que tem como objetivo acompanhar o processo de reestruturação da organização curricular, buscando problematizar as práticas pedagógicas no ensino de Biologia na modalidade EJA, tendo o PROEJA-IFES como campo de investigação. O estudo focaliza, em especial, a problematização e a ressignificação das práticas experimentais, visando a construir coletivamente uma proposta curricular que abranja a abordagem de questóes socioambientais no ensino de Biologia, coerente com a modalidade de EJA, tendo o Meio Ambiente como eixo articulador.

Adotando como estratégia de ação o trabalho colaborativo, os pesquisadores se integraram ao grupo de professores do PROEJA, passando a participar regularmente dos encontros semanais de formação continuada. Esses encontros representam uma conquista dos professores, que se mobilizaram para dispor de um horário comum para as atividades de formação, onde pudessem coletivamente expor suas dificuldades, compartilhar leituras e discutir propostas, a partir das quais definissem alguns marcos conceituais norteadores do processo de reestruturação dos projetos político-pedagógicos dos cursos técnicos do PROEJA. Convém destacar que os pesquisadores se sentiram igualmente desafiados e em nenhum momento manifestaram no grupo a pretensão de intervir verticalmente ou de "dar as respostas" que todos buscavam diante das inquietantes questôes que emergiam dos depoimentos a cada encontro.

Para as análises preliminares do estudo, acompanhamos reunióes do grupo de pesquisa interinstitucional, do qual participam docentes da UFES e do IFES, alunos de pós-graduação e de graduação da UFES, aulas de biologia ministradas para uma turma do curso de Segurança do Trabalho, bem como reuniōes de formação continuada dos professores do PROEJA-IFES que foram uma significativa fonte de dados. Do grupo participam, além dos docentes atuantes no PROEJA, duas pedagogas e a coordenadora do PROEJA, estagiários de cursos de graduação e alunos da Pós-graduação em Educação. Foram também aplicados questionários aos estudantes.

4 Projeto de Pós-doutoramento Júnior, "As práticas experimentais e a abordagem das questôes sociais no ensino de Biologia na reestruturação curricular do PROEJA/ES”, financiado pelo CNPq. 


\section{Os sujeitos do PROEJA: desafios, controvérsias e perspectivas em debate}

O PROEJA foi implantado no IFES em cumprimento ao Decreto no 5.840 , de 13 de julho de 2006, assegurando a oferta do ensino médio integrado à educação profissional na modalidade de educação de jovens e adultos. O ensino médio na modalidade EJA, nesta instituição federal, teve início em 2001 com a implantação do Ensino Médio para Jovens e Adultos Trabalhadores (EMJAT). O EMJAT tinha como público-alvo, jovens e adultos trabalhadores, oriundos das classes populares, com histórico de exclusão educacional. O EMJAT distinguia-se do PROEJA por se tratar de ensino básico voltado para jovens e adultos trabalhadores, sem integrar ao currículo a formação técnica, como no caso do PROEJA. O Documento Base do PROEJA (BRASIL, 2007, p.28) justifica a implementação desta política, apontando como seu principal objetivo a promoção de uma formação fundamentada "na integração de trabalho, ciência, técnica, tecnologia, humanismo e cultura geral" acreditando que ela "pode contribuir para o enriquecimento científico, cultural, político e profissional das populações, pela indissociabilidade dessas dimensões no mundo real". O PROEJA prevê, dentre diversas ações, o desenvolvimento de novos referenciais teórico-metodológicos, pautados na concepção de currículo integrado.

A implementação do PROEJA no IFES foi marcada por uma considerável resistência institucional, já que este programa seria voltado para alunos com um perfil socioeducacional bem diferenciado daqueles que tradicionalmente ingressam na instituição. Havia o receio de que o suposto déficit educacional dos alunos do PROEJA viesse a comprometer a reconhecida qualidade dos cursos técnicos oferecidos. Além disso, os professores admitiam certo despreparo e muita insegurança diante do desafio de construir um novo currículo que integrasse a educação básica e a educação profissional, sem deixar de privilegiar os princípios básicos da modalidade de EJA, desconhecidos pela grande maioria do corpo docente. Esse incômodo manifestado pelos professores sinaliza o quanto a implantação de políticas educacionais reacende as tensōes que atravessam as instituições escolares, algumas delas latentes ou silenciadas pela distribuição heterogênea de poder, pelas diferentes visóes de mundo, os modos diferenciados de eleger as finalidades educacionais e a compreensão das missóes pessoais dos docentes e das comunidades disciplinares que sustentam o trabalho cotidiano na escola.

Segundo Oliveira e Cezarino (2009), o perfil socioeducacional dos estudantes do PROEJA/ IFES confirma o prognóstico apresentado pelo Documento Base, indicando uma diversidade de motivos que levam os alunos a abandonarem a escola e a retornar em busca de melhores condiçôes de empregabilidade, gerando assim um grupo extremamente heterogêneo e repleto de especificidades. Dados da pesquisa dessas autoras obtidos através de questionários aplicados aos alunos do PROEJA/IFES indicam que 38,68\% dos respondentes estiveram afastados da escola 
por um período inferior a 4 anos, enquanto $29,25 \%$ não chegaram a se afastar dos estudos. Somados os dois grupos, verifica-se que $67,93 \%$ dos estudantes tiveram um tempo curto de afastamento do espaço escolar. Verificou-se que 55,67\% dos ingressantes no PROEJA já haviam concluído o ensino médio, dos quais $70 \%$ estudaram em escola pública. Apenas 12,26\% dos estudantes concluíram o Ensino Fundamental por meio de cursos ou exames supletivos.

$\mathrm{O}$ alto índice de estudantes jovens e com o Ensino Médio concluído na rede pública que retornam às salas de aula do PROEJA-IFES em busca da formação técnica, indica uma grande preocupação com a empregabilidade, tendo em vista a inserção num mercado de trabalho competitivo, que exige cada vez mais qualificação profissional. A fim de garantir maiores oportunidade de acesso, o IFES implementou em 2011 mudanças no processo seletivo para ingresso no PROEJA, que deixou de ter a prova objetiva como uma das etapas do processo. Ainda não foi possível avaliar se as reformulaçôes no processo seletivo promoveram alteraçóes significativas no perfil socioeconômico e educacional dos ingressantes.

Essa questão foi um dos objetos de interesse da pesquisa. A participação nos encontros semanais de formação permitiu apreender posições e sentimentos por vezes contraditórios entre os professores, revelando a coexistência de forças e de valores em disputa. Assim, fez-se necessária a realização de entrevistas com professores do PROEJA que pudessem dar voz a esses sujeitos. Diante da heterogeneidade do grupo, havia no decorrer da pesquisa a preocupação em garantir a representatividade das diversas perspectivas existentes entre professores. Assim, optamos por delimitar uma amostra intencional composta por dois elementos da equipe de coordenação do PROEJA, seis professores das disciplinas do módulo básico participantes dos encontros semanais de formação e do processo de elaboração do material didático, três professores que não participavam sistematicamente desses encontros e ainda um professor da formação.

É recorrente, na avaliação dos professores entrevistados, a opinião de que as novas turmas apresentam muitas dificuldades em relação à leitura, escrita e interpretação de textos, o que para eles, inviabiliza o desenvolvimento dos conhecimentos básicos em nível médio. Um dos docentes ressalta que os professores do PROEJA não têm condiçóes adequadas para um trabalho pedagógico eficaz que possa contribuir efetivamente para a superação das dificuldades apresentadas pelos alunos. Afirma o professor:

Nós precisamos admitir o despreparo dos docentes para lidar com essa situação. Enquanto essas condições não forem criadas, alunos com esse perfil não devem ingressar no IFES. A sugestão de alguns docentes é que haja uma seleção que considere e avalie, além do perfil socioeconômico e da trajetória educacional, os conhecimentos básicos de matemática e português 
dos candidatos aos cursos oferecidos. (Prof. A - Curso Técnico em Segurança do Trabalho). Como expresso na fala do professor, percebe-se uma forte preocupação em relação ao perfil dos ingressantes na instituição, o que tem levado muitos docentes a se mobilizarem propondo alteraçóes no processo seletivo. Há, porém, aqueles que consideram que tais alteraçóes representariam um retrocesso, uma vez que o atual processo seletivo valoriza os saberes acumulados socialmente pelos jovens e adultos. Para este grupo de professores, uma alteração na seleção perpetuaria a história de exclusão educacional que marca a trajetória escolar dos sujeitos da EJA. Essas preocupaçóes em relação às necessidades dos alunos expressam uma tensão nas diferentes compreensões dos professores acerca das finalidades do ensino e, certamente, influenciam os processos de reestruturação curricular, conforme abordaremos na próxima seção.

\section{Forças de tradiçáo e renovaçáo no processo de reestruturaçáo curricular e elaboraçáo de materiais didáticos no PROEJA}

No percurso histórico do IFES, percebe-se um conflito entre forças de renovação e forças de tradição, que configuram um movimento ambivalente em que se pretende preservar o prestígio social da instituição, vista como escola tradicional centenária, ao mesmo tempo em que se buscam estratégias pedagógicas inovadoras que possibilitem o enfrentamento das demandas ocasionadas pelas dinâmicas históricas, como, por exemplo, a vivida pela implementação do PROEJA.

Durante os encontros semanais de formação continuada dos professores do PROEJA, vem se configurando um fórum permanente de discussão e de avaliação de concepçóes e práticas que vão se construindo coletivamente. Nesses encontros, é recorrente a ideia de que o maior entrave para a aprendizagem dos alunos, além do déficit educacional desses sujeitos, é o tempo reduzido destinado a cada disciplina. Muitos professores se queixam do fato de os alunos não disporem de tempo para se dedicarem ao estudo extraclasse. Nesse sentido, uma das professoras destaca:

[...] a primeira e a última aula são geralmente as mais prejudicadas, pois muitos alunos chegam atrasados, devido ao horário de saída do trabalho, e outros saem mais cedo porque estáo exaustos ao final do dia. Eles também não têm muito tempo para estudar em casa. (Profa B - Curso Técnico de Metalurgia).

Percebe-se a predominância de uma concepção de aprendizado muito centrada no esforço individual do estudante, segundo a qual caberia aos alunos se esforçar e estudar mais fora da escola. Além disso, das discussões nos encontros de formação emergem outras constataçôes que começam a ganhar força entre os professores, produzindo um movimento em busca de novas alternativas 
metodológicas. A primeira constatação reafirma a importância da revisão e da reestruturação dos currículos vigentes nos cursos técnicos do IFES, tendo em vista a elaboração de novas propostas curriculares que contemplem as especificidades dos sujeitos do PROEJA. A segunda constatação aponta para a carência de recursos didáticos específicos para o PROEJA e para a necessidade de mobilização de esforços para criação de materiais didáticos adequados aos princípios, objetivos e demandas do PROEJA/IFES. Nesse sentido, já se observam os primeiros resultados.

Considerando os objetivos da presente etapa deste estudo, interessa-nos focalizar, em especial, aspectos relativos ao ensino das disciplinas da área de Ciências da Natureza (Biologia, Física e Química), incluindo a elaboração de materiais didáticos, tarefa que envolve, além dos professores do PROEJA, pesquisadores da UFES e graduandos que desenvolvem projetos de Iniciação Científica. Para tanto, os procedimentos metodológicos adotados neste estudo incluíram um período de acompanhamento das aulas de Biologia do curso de Segurança do Trabalho e o acompanhamento das reuniōes para discussão da elaboração do material didático.

Nesse processo de coleta de dados foram observadas as aulas numa turma do turno vespertino, com a colaboração de uma bolsista de Iniciação Científica que auxiliava nos registros das atividades. As observações se estenderam por um período de três meses. Durante as aulas observadas, convém destacar o empenho de um dos professores de Biologia, que sempre buscava alternativas didáticas que promovessem maior envolvimento dos alunos com os conceitos biológicos. Contudo, era também perceptível a ênfase no conteúdo específico da disciplina, sem uma relação explícita com as experiências concretas vivenciadas pelos alunos.

Essa percepção tornou-se clara numa das experiências observadas em turmas do turno vespertino, em que aulas práticas foram realizadas na parte externa do prédio, mais especificamente nos jardins, para observação das espécies vegetais ali presentes. O objetivo da atividade era a identificação das plantas e o levantamento de impressóes dos alunos acerca do projeto paisagístico do campus, estimulando o trabalho cooperativo entre os alunos, bem como a aquisição de conceitos relacionados à Taxonomia Botânica, Fisiologia Vegetal e Ecologia de paisagem. Para trabalhar os conteúdos relacionados à Ecologia de Ecossistemas os alunos participaram de uma visita monitorada à ECBH - Escola da Ciência - Biologia e História, que é uma das quatro Escolas da Ciência mantidas pela Prefeitura de Vitória (ES). $\quad \mathrm{Na}$ ECBH os alunos puderam observar representaçóes de ecossistemas aquáticos e terrestres do estado do Espírito Santo.

Um dos pesquisadores que acompanhava a atividade chegou a indagar do professor por que não ampliar a atividade, incorporando à abordagem dos aspectos ecológicos, temas de profunda relevância socioambiental e econômica no Espírito Santo. Foi 
mencionado, entre outros temas, o debate sobre a preservação dos manguezais em face das atividades extrativistas dos catadores e das desfiadeiras de caranguejo, assim como das associaçóes das paneleiras, que utilizam sedimentos e pigmentos do mangue na confecção das tradicionais panelas de barro, ícone da cultura gastronômica capixaba.

Outras temáticas sugeridas foram a polêmica em torno da monocultura do eucalipto para produção de celulose e seu impacto sobre a agricultura familiar e a produção de alimentos no interior do estado, o impacto da poluição sobre as atividades pesqueiras artesanais, a influência das atividades de mineração, ampliadas pela exploração de petróleo e gás e de mármore e granito sobre o modo de vida das comunidades, incluindo o lazer e o turismo, a ocupação desordenada do espaço em algumas áreas da região metropolitana e os consequentes prejuízos na qualidade de vida da população pobre. Diante dessas sugestôes, o professor argumenta:

Sem dúvida, tudo isso é muito relevante. Mas se a gente for falar disso tudo, acaba perdendo o foco da matéria, que é a Biologia. Eu não sei se sou capaz de conduzir essa discussão... Aí vai ficando tudo muito difuso. Os conceitos acabam sendo abordados muito superficialmente. Essa parte mais social eu acho que é da competência das áreas de Ciências Humanas. (Prof. D - Curso de Segurança do Trabalho)

Sabemos que a realização de atividades diversificadas nas aulas de Biologia por si só não garante uma abordagem mais crítica e contextualizada dos conteúdos, exigindo dos docentes tanto uma reflexão mais profunda acerca das finalidades destas aulas quanto um ajuste às condiçóes institucionais - e curriculares - que lhes permitam superar um modo de dinamismo descontextualizado. Cabe lembrar que a implementação dessa perspectiva é complexa e nem sempre repousa exclusivamente no desejo dos professores. Muitas vezes, como evidenciado na citação anterior, estes são cônscios do valor desta abordagem, mas sua realização esbarra em obstáculos de ordem institucional e de carreira docente o que frustra uma atuação com as características sugeridas. Com efeito, nas aulas observadas percebe-se a dificuldade por parte do professor para incorporar ao ensino de Ciências/Biologia o debate de questóes sociais mais amplas, sem desconsiderar as especificidades desta área do conhecimento, o que reforça a percepção de que a tendência tecnicista é um refúgio pedagógico que persiste no ensino dessa disciplina.

O IFES conta com modernos laboratórios e oficinas, equipados de acordo com a especificidade do conteúdo de cada área de conhecimento. Ainda assim, as atividades experimentais no PROEJA raramente estão relacionadas com a abordagem de questôes sociais, conforme 
argumentam os currículos da EJA. Essa abordagem não impõe o abandono do ensino experimental, defendido como capaz de aproximar o aluno do trabalho científico e tecnológico. Essa articulação é defendida por Magalhães e Tenreiro-Vieira (2006), pois, para as autoras,

A educação em Ciências deve estar em conformidade com duas finalidades. Uma diz respeito à compreensão das relações entre a Ciência, a Tecnologia e as diferentes esferas da Sociedade e a outra ao uso, pelos alunos, de capacidades de pensamento, nomeadamente de pensamento crítico, na tomada de decisão e na resolução de problemas a nível pessoal, profissional e social". (MAGALHÁES e TENREIRO-VIEIRA, 2006, p. 86).

Se o valor das atividades experimentais pode ser defendido tanto para a formação geral dos alunos quanto para oscursos técnicos, convém ressaltar quea realização de atividades práticas, por si só, não assegura o desenvolvimento das capacidades de observação e argumentação crítica. Na experiência do PROEJA no IFES, as práticas laboratoriais orientadas por uma visão tecnicista e instrumental de ensino, em que não só os conhecimentos, mas também os espaços e os tempos escolares são compartimentalizados, parece contribuir muito pouco para a formação com vistas à emancipação dos sujeitos. Essa visão influencia também a seleção e a organização dos conteúdos curriculares.

\section{A ênfase tecnicista no ensino de Ciências no PROEJA}

Enquanto no documento base do PROEJA preconiza-se uma organização curricular flexível, com ênfase na "integração teoria-prática, entre o saber e o saber-fazer" (p. 34), o que se observa na prática pedagógica é a manutenção de uma matriz curricular com caráter tecnicista, posto que essa integração é incorporada como metodologia e não como uma concepção de ensino para essa modalidade educacional. As atividades experimentais são valorizadas como necessárias ao desenvolvimento de habilidades técnicas, porém realizadas num curto espaço de tempo, apenas para demonstrar conceitos apresentados previamente nas aulas expositivas.

A infraestrutura do IFES aliada ao nível de qualificação de seu quadro docente, composto por um número significativo de mestres e doutores, pesquisadores das diversas áreas tecnológicas, torna compreensível a valorização do ensino experimental nos seus currículos, que assegura ao IFES posição privilegiada em relação à maioria dos estabelecimentos de ensino Médio em nosso país, onde a falta de regularidade - e mesmo, ausência, em inúmeras instituiçôes - do ensino experimental é historicamente registrada. 
A título de exemplo, podemos mencionar uma situação que ilustra a predominância de uma concepção instrumental de ensino, ocorrida no momento em que alguns professores discutiam a distribuição da carga horária das disciplinas na nova matriz curricular do Curso Técnico de Construçáo Civil do PROEJA. O grupo concluiu que a carga horária destinada às aulas de Matemática, Física e Química deveria ser mais extensa, considerandose a relevância dos conhecimentos dessas áreas para a elaboração das plantas e dos projetos elétricos e hidráulicos, bem como para a adequada seleção dos materiais usados na construção civil. Com relação aos conteúdos essenciais da disciplina de Biologia, foi sugerida a abordagem de temas relacionados ao meio ambiente e à saúde que pudessem estabelecer relação direta com o foco principal do curso, tais como o saneamento básico e a conservação dos recursos hídricos, a botânica aplicada ao paisagismo, dentre outros.

Chama a atenção o fato de os professores terem encontrado dificuldades, em princípio, para justificar a distribuição proporcional da carga horária entre as disciplinas da formação geral, ficando evidente a hierarquização dos componentes curriculares dentro de uma visão instrumental do currículo, referenciada tâo somente nas exigências do saber-fazer profissional. Este fato ilustra o quanto as decisões curriculares no interior das instituições escolares são atravessadas por critérios que não são apenas epistemológicos. Essas disputas também estão se dando para reivindicar espaços e tempos disciplinares, nas quais estão em jogo distintas compreensões das finalidades escolares e as possibilidades de articulaçóes políticas destes sujeitos.

Longe da pretensão de assumir uma postura prescritiva ou de interferir na dinâmica institucional propondo alternativas metodológicas para o PROEJA, interessa-nos neste momento da pesquisa delimitar alguns recortes teóricos, que nos permitam compreender melhor os processos observados no campo investigado e as finalidades da educação científica em questão. Com base em autores como Goodson (1995), Rosenthal \& Bybee (1987) e Tracey (1962), entre outros, Selles e Ferreira (2005) nos indicam a existência de uma oscilação histórica entre as diferentes finalidades das disciplinas escolares, que ora tendem a valorizar as próprias ciências de referência, ora enfatizam a utilidade e o valor social desses conhecimentos.

Segundo Goodson (1995), tanto as finalidades de caráter utilitário, que focalizam conhecimentos de natureza prática e técnica, quanto as finalidades de caráter pedagógico, que valorizam os conhecimentos referenciados nas experiências cotidianas, com claras implicações sociais, expressam um processo de seleção de conteúdos escolares que leva em conta a relevância social desses conteúdos e, consequentemente, dos métodos de ensino. 
O autor ressalta também a existência de finalidades acadêmicas, referenciadas na tradição universitária, que priorizam conhecimentos teóricos, dotados de valor em si mesmos, dispensando qualquer justificativa para a sua inclusão no currículo escolar. Selles e Ferreira (2005) entendem que essas finalidades que perpassam a trajetória das

disciplinas escolares não são mutuamente excludentes. Pelo contrário, analisada de um ponto de vista histórico, essa oscilação - e muitas vezes superposição - auxilia a compreensão dos objetivos plurais dos conhecimentos biológicos nos currículos escolares.

A proposição de uma nova matriz curricular e de novas metodologias de ensino para o PROEJA requer um olhar complexo sobre as finalidades da educação científica e tecnológica associadas com elementos de ordem política e social. Nesse sentido, buscamse modelos de ensino que contemplem a formação científica e tecnológica, enfatizando a sua relação com o mundo do trabalho, sem perder de vista as especificidades de seus sujeitos e o caráter político que sempre caracterizou a trajetória histórica da EJA.

Visando a aprofundar a compreensão do tratamento dado a essas questóes em nível internacional, buscamos conhecer in loco a experiência do Programa de Formação Contínua de Professores do $1^{\circ}$ Ciclo do Ensino Básico em Ensino Experimental das Ciências (PFEEC) do Centro de Investigação Didáctica e Tecnologia na Formação de Formadores, da Universidade de Aveiro, Portugal. Trata-se de uma proposta de ensino experimental contextualizado, centrado na abordagem de questóes socioambientais, que defende o trabalho docente colaborativo como condição fundamental para a implantação de novos modelos curriculares. Nestes aspectos, percebemos algumas similaridades com a proposta de ensino experimental que consideramos adequada aos princípios básicos e objetivos do PROEJA, razão pela qual o acompanhamento da experiência portuguesa nos pareceu bastante elucidativo e enriquecedor.

\section{A experiência do PFEEC no processo de reorganização curricular em Portugal}

No período de setembro a novembro de 2010, acompanhamos as atividades do CIDTFF, procurando conhecer a contribuição daquele centro de pesquisa para a formação continuada de professores de Ciências, especialmente no que diz respeito ao ensino experimental, considerado obrigatório no atual currículo nacional português. 
Essa experiência tem se mostrado especialmente relevante para a elaboração de um repertório de ações pautadas na relação Ciência, Tecnologia e Sociedade. O enquadramento teórico do PFEEC se constitui a partir da produção de autores portugueses como Antonio Cachapuz, Rui Vieira, Celina Tenreiro-Vieira, Isabel Martins, Nilza Costa, Idalina Martins e Marta Abelha5. Além desses, pesquisadores brasileiros estudiosos do currículo e de suas matrizes históricas e culturais, em especial na área das Ciências, têm embasado nossas reflexóes acerca das similaridades e peculiaridades das políticas e práticas curriculares no Brasil e em Portugal, com vistas ao desenvolvimento de estratégias de ensino que levem em conta os resultados dessas investigações.

Embora voltado para professores dos anos iniciais, o PFEEC se reveste de especial relevância pela abrangência de sua implementação, em nível nacional, no rastro dos projetos de reorganização curricular no país, iniciados na década de 1990. A concepção do programa é marcada pela busca de referenciais teórico-metodológicos que promovam a articulação entre o ensino experimental em Ciências e a abordagem de questóes socioambientais associadas ao conhecimento científico e tecnológico.

O PFEEC se apoia, portanto, em uma concepção de ensino experimental, que toma como ponto de partida a abordagem didática de fenômenos observados no cotidiano, conforme sugerem as novas diretrizes curriculares portuguesas. Não obstante, o caráter diretivo das atividades propostas em forma de guias didáticos, o PFEEC busca superar uma tendência de experimentação que se aproxima das visóes comportamentalistas de Educação Ambiental, centradas na atividade e nos aspectos lúdicos. Ao contrário, o PFEEC preconiza uma abordagem de Educação Ambiental crítica e emancipadora, na medida em que busca sensibilizar os professores para a adoção de práticas investigativas, que não apenas propiciem a observação dos fenômenos físicos, químicos e biológicos, mas que, principalmente, estimulem atitudes responsáveis em relação aos problemas socioambientais.

O programa teve como principal saldo positivo o envolvimento de um número muito significativo de professores, de todas as regiōes do país, que, tendo vivenciado as atividades sugeridas, diziam-se entusiasmados com as possibilidades pedagógicas proporcionadas pela experiência e instigados para desenvolver o ensino experimental em suas salas de aula. Contudo, a implementação dessas novas diretrizes encontrou entre os professores portugueses obstáculos muito semelhantes aos enfrentados no âmbito do PROEJA.

5 Os referidos pesquisadores integram ou já integraram o corpo docente do Centro de Investigação Didáctica e Tecnologia na Formação de Formadores, da Universidade de Aveiro, Portugal. Sua produção tem apoiado pesquisas brasileiras a exemplo de Bernardo (2011) e Ferreira, Martins e Abelha (2010). 
Os resultados dos estudos de Martins (2005) documentam as dificuldades de os professores portugueses vivenciarem o currículo como um projeto que se constrói e reconstrói em função da intervenção e da intencionalidade de diferentes atores. As novas orientaçóes curriculares daquele país propóem a organização colaborativa dos processos, estimulando, inclusive, práticas de co-docência ou par pedagógico, prática ainda desconhecida e muito pouco difundida entre os professores. Neste aspecto, percebe-se certa similaridade entre as orientaçóes portuguesas com as diretrizes curriculares brasileiras, que também

apontam as vantagens do trabalho docente colaborativo, em especial na modalidade de EJA. No entanto, por razóes que não nos cabem aprofundar neste artigo, essas propostas ainda soam como ideais distantes do vivido no cotidiano escolar, tanto lá, como aqui.

Segundo Costa et al. (2008), prevalecem nas escolas portuguesas práticas pedagógicas e planos de ensino em que a noção de competência, que fundamenta o currículo nacional português, ainda é confundida com objetivos de ensino. Como destaca Macedo (2002), a noção de competência tem circulado - tanto no Brasil quanto na Europa ${ }^{6}$ - em publicações e políticas curriculares, associada a variados sentidos. Para a autora, além da dimensão cognitivaconstrutivista a ela atribuída - como modalidades estruturais da inteligência, ressaltando seu papel na construção de conhecimentos - que se expressa em comportamentos observáveis ${ }^{7}$, a noção de competência tem sustentando reformas educativas como princípio de organização curricular ${ }^{8}$. Portanto, as evidências anunciadas por Costa et al. (2008) reforçam que a associação a objetivos de ensino, apropriada por docentes, é problemática e mostra a complexidade das demandas requeridas para a sustentação pedagógica das mudanças curriculares. Em relação à participação docente nessas mudanças, o estudo de Costa et al. (2008) também documenta que a excessiva compartimentalização disciplinar, a exemplo do que também ocorre no Brasil, é apontada pelos professores como um problema do sistema educativo em Portugal, por dificultar a construção coletiva de um sólido projeto de reorganização dos currículos e das práticas docentes.

\footnotetext{
6 Uma diversidade de significados é apontada por Isambert-Jamarti (1994) em estudo realizado sobre a realidade européia. (ISAMBERT-JAMARTIM, V. L'appel à notion de compétence dans la Reveu L'Orientacion Scoilaire et Profissionelle à as naissance et aujourd 'hui. In: Ropé, R; Tanguy, L. Savoirs et compétences: de l'usage de ces notions dans l'ecole et l'entreprise. Paris: L'Harmattan, 1994. apud MACEDO, 2002),

7 Segundo a autora, tal concepção está presente nas matrizes curriculares de referência do Sistema de Avaliação da Educação Básica (SAEB) brasileiro.

8 Segundo a autora, tal concepção está presente nas matrizes curriculares de referência do Sistema de Avaliação da Educação Básica (SAEB) brasileiro.
} 
Martins (2005) assinala que a apropriação da atual abordagem curricular voltada para o desenvolvimento de competências ainda é bastante incipiente, encontrando-se num estágio embrionário. Há que se reconhecer, no entanto, o esforço de buscar concepções de ensino fundamentadas numa concepção que articule os conhecimentos escolares de cunho científico aos usos sociais desses conhecimentos, relacionando-os às vivências cotidianas dos sujeitos envolvidos no processo de ensino e aprendizagem. No ensino de Biologia, por exemplo, os desafios de problematizar as questóes socioambientais entendendo-as como possibilidades de provocar diferentes visóes de mundo, pressupóe um processo que questiona padróes conservadores, ao mesmo tempo em que tece alternativas para seu enfrentamento.

\section{Rupturas e tessituras no processo de elaboração do material didático no PROEJA/ES}

Enquanto no documento base do PROEJA indica-se uma organização curricular flexível, com ênfase na "integração teoria-prática, entre o saber e o saber-fazer" (BRASIL, 2007, p. 34), o que se observa na prática pedagógica é a manutenção de uma matriz curricular com caráter tecnicista, em que as atividades experimentais são valorizadas como necessárias ao desenvolvimento de habilidades técnicas, porém realizadas num curto espaço de tempo, para demonstrar conceitos apresentados previamente nas aulas expositivas. Os professores sentem a necessidade de superar tais modelos pedagógicos que, historicamente, encontramse enraizados às práticas escolares, inclusive no ensino de Biologia, a despeito de tradições de caráter experimentalista ou prático que nele perpassam. Assim, a busca de alternativas que deem materialidade a alguns dos princípios básicos norteadores do trabalho pedagógico no PROEJA motivou um grupo de professores a conjugar esforços na produção de materiais didáticos que concretizassem a compreensão coletiva acerca do currículo que começava a ganhar densidade.

O primeiro grupo a se mobilizar para a elaboração de material didático foram os professores da área de Matemática, cuja experiência é relatada por Freitas e Jordane (2009). Segundo os autores, a primeira questão considerada no processo de construção de um material didático para o PROEJA foi a definição das concepçóes que deveriam permear o material didático. Simultaneamente, foram avaliados criteriosamente os materiais didáticos disponíveis para o trabalho no ensino médio no IFES, buscando-se fundamentar a opção por produzir um novo material em vez de fazer uso do material já disponível.

Atualmente, outros grupos de professores, em sua maioria responsáveis pelas disciplinas da área de Ciências Humanas, vêm se envolvendo no processo de elaboração de materiais didáticos para o PROEJA. Nesse processo, buscam contemplar a relação entre educação profissional, 
ensino médio e educação de jovens e adultos, o diálogo com espaços de produção de saberes na sociedade, as trajetórias e experiências de vida dos alunos como ponto de partida, os saberes em diferentes espaços sociais, o uso da tecnologia, a abordagem interdisciplinar e contextualizada dos conceitos, a definição de temáticas e conteúdos específicos para a EJA, a autonomia nas ações dos estudantes e, por fim, a valorização da cultura e da história local, regional, nacional e global. Desta forma, busca a construçâo do diálogo e da criticidade, valorizando a liberdade e as particularidades dos alunos jovens e adultos (FREITAS e JORDANE, 2009). A temática ambiental foi escolhida como o eixo articulador do currículo para produção do material didático curricular. A análise das primeiras versões do material didático

permitiu detectar a predominância de um enfoque interdisciplinar, que visa a abordar a problemática ambiental para além da perspectiva estritamente biológica, englobando também as implicaçôes sociais, políticas e econômicas relacionadas às questôes ambientais.

O material consiste em um conjunto de sequências didáticas que abordam componentes curriculares das diversas disciplinas. As sequências se estruturam a partir de textos introdutórios variados (letra de música, poema, imagens, matéria jornalística ou texto informativo), aos quais se integram questôes subjetivas, que visam a subsidiar a reflexão e o debate em sala de aula de temas de interesse social, como: preservação ambiental; desenvolvimento sustentável; economia solidária; meios de produção; organização social do trabalho; movimentos sociais, etc. Os conteúdos das diversas disciplinas, apresentados em forma de textos informativos, perpassam as atividades propostas, visando a contribuir para a melhor compreensão do tema.

Para exemplificar, podemos mencionar a sequência didática que teve como texto introdutório letras de músicas com foco na temática ambiental, como "Sal da Terra", de Beto Guedes e "Pindorama" de Sandra Peres e Luiz Tatit. Em seguida, são propostas diversas atividades que envolvem a análise dos diferentes gêneros textuais e a exposição de aspectos históricos e geográficos. Por fim, o material propóe a leitura da Carta de Pero Vaz de Caminha', sugerindo atividades que levam à comparação entre o cenário descrito por Caminha na ocasiāo do descobrimento e as transformações que experimentamos no Brasil de hoje.

\footnotetext{
9 Cabe destacar que a Carta de Caminha abre a coletânea organizada por Marcos Reigota (2001) com textos de estudiosos da Educação Ambiental. Tratando a carta como "arqueologia histórica e imaginária” Reigota justifica sua escolha para a abertura do livro para "desconstuir vícios e equívocos" (p. 11) da Educação Ambiental. O organizador justifica a carta como “documento 'obrigatório' que deve estar presente nas atividades de Educação Ambiental” (p. 10), o que indica a circulação deste documento entre a comunidade de educadores e pode justificar a escolha dos docentes.
} 
Encontra-se subjacente nos textos do material didático produzido pelos professores a noção de desequilíbrio, seja na harmonia dinâmica dos processos ecossistêmicos, seja nas relações entre os homens e destes com a natureza. Assim, o desequilíbrio ambiental é visto como consequência direta do modelo de desenvolvimento econômico e do tipo de racionalidade envolvida.

É possível dialogar essas evidências com o trabalho de Mazzotti (1997) quando realizou uma extensa pesquisa na qual examinou as representaçóes sociais de problema ambiental elaboradas tanto por professores e estudantes da educação básica quanto por lideranças comunitárias. Cada um dos grupos investigados por Mazzotti, a partir de sua própria perspectiva, tem importante papel na composição dos conceitos de ambiente e problema ambiental difusos na sociedade, ora como agentes de sistematizaçâo dos conhecimentos construídos pela via da escolarização, ora como atores num processo de reelaboração desses conceitos em suas práticas sociais. Ao conceito de ambiente está vinculada, de forma indissociável, a noção de "problema ambiental", que assume diferentes níveis de complexidade, dependendo do contexto. $\mathrm{O}$ autor foi buscar entre as linhas de pesquisa da Psicologia Social os aportes teóricos que demonstrassem maior capacidade explicativa para a prevalência dessas concepções em relação à concepção de "problema ambiental”. Em publicação anterior a esta, Reigota (1995) também relatou os resultados de sua investigação sobre a representação social de "ambiente" entre professores de Ciências e Biologia e constatou resultados muito semelhantes aos obtidos por Mazzotti.

Reigota verificou que os professores atribuíam ao homem (como ser genérico) o papel de "depredador por excelência". A superprodução de lixo, a poluição e o desmatamento foram os problemas mais recorrentes no discurso dos professores, que apontaram as atividades econômicas e o modelo capitalista, centrado na lucratividade, como causas primárias dos desequilíbrios ambientais. Por sua vez, Mazzotti vai além quando se propóe a levantar as representações sociais dos professores, comparando-as às de estudantes e lideranças comunitárias.

A maioria dos professores do PROEJA envolvidos no processo de elaboração do material didático compartilham a ideia de que intervençôes humanas sobre a natureza são motivadas pela ganância dos grandes grupos econômicos, sendo esta a principal causa para o desequilíbrio ambiental e climático. Para esses professores, o problema ambiental assume configuração mais política, segundo a qual, o maior enfrentado pela população estaria relacionado às desigualdades sociais que se expressam nos baixos salários, na má qualidade da alimentação, nas condiçóes de moradia e nos serviços públicos de saúde, descaso em relação ao tratamento do lixo e à falta de saneamento básico. 
Em geral, os professores concordam que é papel da educação e não apenas do ensino de Biologia, contribuir para o desenvolvimento de uma consciência ambiental, que repudie as agressóes ao meio ambiente, evitando, dessa forma, as consequências desastrosas que poderão comprometer ainda mais a qualidade de vida das comunidades. Os professores manifestam em suas falas muita clareza em relação aos fatores sociais e políticos envolvidos nas questóes ambientais. Dentre as temáticas que permitem fazer esta associação, a saúde é mencionada como uma das possibilidades de tratamento no ensino de Biologia. As falas sugerem que os aspectos biológicos desta temática podem estar subordinados a noçóes mais críticas, de modo a enfatizar o caráter socioambiental. Além disso, parece haver uma agenda para este tratamento que é a marca do tipo de instituição que os alunos frequentam. Assim, vê-se que ambiente, biologia e formação profissional não estão desvinculados, ainda que reconheçam que têm diante de si o desafio de articular a crítica social aos conteúdos curriculares ligados à temática ambiental:

Acho que é fundamental que o ensino de Biologia dê uma noção de meio ambiente e também de como lidar com as coisas importantes ligadas à saúde, por exemplo. Meio ambiente e saúde estão interligados. Sabendo disso, nosso aluno pode ajudar sua comunidade através de orientaçóes que leva para dentro de casa. No nosso caso ainda há a questão da formação profissional. Ele tem que ser um profissional consciente dos riscos ambientais para si próprio, para o ambiente de trabalho e para a sociedade. É tudo muito articulado, muito complexo [...] (Professor C-Educação Básica).

\section{CONSIDERAÇÓES FINAIS}

Ao questionar "por onde avançar no ensino de Ciências”, Arroyo (1988, p. 3) já apontava uma série de componentes: "os sujeitos docentes, os conteúdos, os livros de texto, os processos de transmissão-avaliação, os sujeitos cognoscentes, os contextos de sala, os laboratórios... Há muito campo para repensar cada um desses aspectos".

Mais de duas décadas depois da constatação do autor, há ainda muito para caminhar.

A discussão acerca do papel social do ensino de Biologia representa hoje mais que uma reflexão pedagógica ou epistemológica sobre saberes, métodos e conteúdos. Insere em seu bojo questôes muito amplas, que exigem uma contextualização histórica, social e política.

No PROEJA concretiza-se a relação do ensino de Biologia com a educação profissional no contexto da EJA. Este novo espaço de formação tem contribuído para apontar possíveis lacunas, que devem ser levadas em conta pelas instituições formadoras. É preciso discutir e propor 
objetivos, conteúdos e métodos de ensino de Biologia que permitam preparar os estudantes para as exigências do mundo competitivo em que vivemos, sem, no entanto, perder de vista o papel social deste ensino, que está relacionado com a formação para o exercício pleno da cidadania. A proposição de uma nova matriz curricular e de novas metodologias de ensino para o PROEJA requer um olhar complexo sobre as finalidades da educação científica e tecnológica associadas com elementos de ordem política. Busca-se um ensino que articule as especificidades dos sujeitos da EJA, a sua relaçáo com o mundo do trabalho e a abordagem crítica das questóes sociais, que sempre caracterizou a trajetória histórica da EJA, sem perder de vista a formação científica e tecnológica a que se propõe o programa. Essas diversas dimensóes não só reforçam a complexidade deste empreendimento, como também apontam uma agenda de pesquisa e de intervenção neste campo, conforme sugere Arroyo.

A postura não prescritiva assumida na pesquisa tem servido para advertir a equipe de pesquisadores que não é possível interferir na dinâmica institucional propondo alternativas metodológicas para o PROEJA, sem que esta postura comprometa o caráter coletivo assumido nesta construçáo. Os recortes teórico-metodológicos vêm nos permitindo compreender melhor os processos observados no campo investigado e considerar as diferentes visóes dos sujeitos sobre as finalidades da educação científica no IFES. Isto porque, se consideramos que a construção científica e tecnológica responde a demandas da sociedade ao mesmo tempo em que cria outras, a educação escolar de cunho científico agrega finalidades utilitárias, pedagógicas ao lado das acadêmicas, as quais historicamente vêm sendo mais valorizadas - pelo menos na educação não profissional. Entretanto, as finalidades de ordem política e social ganham relevância no processo de construção curricular relatado, pois elas não se encontram desvinculadas do contexto e das circunstâncias que motivaram a produção científica e tecnológica. Por estar referenciado nas experiências cotidianas, esse processo é produção cultural e, portanto, assume-se como construçãocoletiva e histórica.

O grande desafio que se coloca para os professores e investigadores da área de ensino de Biologia em geral, e na EJA em especial, é a formulação de propostas pedagógicas mais inclusivas, que possibilitem romper com a visão reducionista e meramente instrumental do conhecimento biológico, especialmente dos conceitos fundamentais e de grande relevância social, como é o caso da noção de ambiente, destacada ao longo do artigo.

Os depoimentos dos professores entrevistados sugerem que a articulação de questóes de cunho social mais amplo aos conteúdos de Biologia, Física e Química precisa ser intensificada. A diversidade de linguagens, culturas, necessidades, desejos e incertezas que confluem para os espaços plurais das salas de aula nem sempre conseguem estabelecer, com a linguagem hermética da Biologia, o diálogo fluente e significativo que esperamos, mesmo 
quando consideramos que nelas já tenha havido ressignificações do conhecimento biológico produzido nas instâncias acadêmicas e científicas ${ }^{10}$. O caminho está aberto para novas incursôes, que visem ao aprofundamento ou desdobramentos dos aspectos até aqui levantados.

\section{REFERÊNCIAS}

ARROYO, A. A função social do ensino de Ciências. Em Aberto. Brasília, n. 40, p. 3-11, 1988.

BERNARDO, J. R. R. ; VIANNA, Deise Miranda ; SILVA, V. H. D. . A Construção de Propostas de Ensino em Ciência-Tecnologia-Sociedade (CTS) para Abordagem de Temas Sociocientíficos. In: Wildson Luiz Pereira dos Santos; Décio Auler. (Org.). CTS e Educação Científica: desafios, tendências e resultados de pesquisas. CTS e Educação Científica: desafios, tendências e resultados de pesquisas. $1^{\text {a }}$ ed. Brasília: UnB, 2011, v. 1, p. 373-393.

FERREIRA, M. S. ; MARTINS, I. ; ABELHA, M. Políticas de currículo para o ensino da disciplina escolar Ciências: aproximaçóes e distanciamentos entre Portugal e Brasil. In: Maria de Lourdes Tura; Carlinda Leite. (Org.). Questóes de currículo e trabalho docente. Questóes de currículo e trabalho docente. 1ed. Rio de Janeiro: Quartet/FAPERJ, 2010, p. 213-229.

FREITAS, Rony Cláudio de Oliveira ; JORDANE, Alex . Material Didático de Matemática para o PROEJA: Uma Construção Colaborativa. Publicação online: http://forumeja.org.br/ files/Material\%20proeja.pdf. In: SINECT - I Simpósio Nacional de Ensino de Ciência e Tecnologia, Ponta Grossa-Pr, v. 1. 2009, p. 948-970.

GOODSON, I. F. Currículo: Teoria e História. Petrópolis: Vozes, 1995.

MACEDO, E. Currículo e Competência. In: LOPES, A.C. e MACEDO, E. Disciplinas e integração curricular: Histórias e Políticas. Rio de Janeiro: DP\&A, 2002.

MAGALHÂES, S. I. R. \& TENREIRO-VIEIRA, C. Educação em Ciência para uma articulação Ciência, Tecnologia, Sociedade e Pensamento Crítico. Um programa de formação de professores. Revista Portuguesa de Educação. 19(2), p. 85-110, 2006.

10 Referimo-nos ao entendimento de que o conhecimento escolar não é uma mera simplificação do conhecimento biológico (ver Marandino et al. 2011). 
MARANDINO, M.; SELLES, S.E. e FERREIRA, M.S. Ensino de Biologia: histórias e práticas em diferentes espaços educativos. São Paulo: Ed. Cotez, 2011. 1ª reimpressão.

MAZZOTTI, T. Representação social de "problema ambiental": uma contribuição à Educação Ambiental. Revista Brasileira de Estudos Pedagógicos. Brasília, v. 78, n. 188/189/190, p. 86-123, 1997.

. Uma crítica da "ética" ambientalista. In: Ciência, Ética e Cultura na Educação. São Leopoldo: Ed. UNISINOS, 1998.

MEC/SETEC/PROEJA. Documento Base. Programa Nacional de Integração da Educação Profissional com a Educação Básica na Modalidade de Educação de Jovens e Adultos. Brasília: SETEC/MEC, 2007.

OliveirA, E. C. de; CEZARINO, K. R. A.; SANTOS, J. S. Sujeitos da Educaçáo de Jovens e Adultos no PROEJA. In: XXIV Simpósio Brasileiro - III Congresso Interamericano de Política e Administração da Educação, 2009, Vitória. Direitos humanos e cidadania: desafios para as políticas e a gestão democrática da educação. v. 08 p. 177-177, 2009.

REIGOTA, M. Meio ambiente e representação social. São Paulo: Cortez, 1995. REIGOTA, M. (org.). Verde cotidiano: o meio ambiente em discussáo. Rio de Janeiro: DP\&A, 2001.

ROSENTHAL, D. B.; BYBEE, R. W. Emergency of the Biology curriculum: a science of life or a science of living? In: POPKEWITZ, T. The Formation of School Subjects: the Struggle for Creating an American Institution. London: Falmer Press, 1987. p. 123-144.

SELLES, S. E.; FERREIRA, M. S. Disciplina escolar Biologia: entre a retórica unificadora e as questôes sociais. In: MARANDINO, Martha et al. (Org). Ensino de Biologia: conhecimentos e valores e valores em disputa. Niterói: Eduff, 2005. p. 50-62.

TRACEY, G. W. Biology - its struggle for recognition in English Schools during the period 1900-1960. The School Science Review, 93, 1962, p. 423-433. 